NOTAS

\title{
LA NOCIÓN DE PROGRESO DESDE APEL Y HABERMAS Ricardo Marcelino Rivas*
}

RESUMEN: El presente trabajo toma en cuenta las críticas hechas a la idea moderna de progreso que, al haberse identificado con la razón instrumental, provocó en la historia consecuencias funestas. Esto 'concedió razón' a los críticos de la razón para declarar el "Fin del sentido de la historia"; sin embargo, nos proponemos hacer una relectura de dicha idea tomando como marco conceptual la ética del discurso, representada por K.O. Apel y J. Habermas, quienes buscan recuperar el potencial emancipador de la razón y mantienen una perspectiva de sentido para la historia.

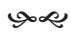

ABSTRACT: This paper considers the criticisims by which the modern idea of progress has undergone and provoqued negative consequences in history when it was equated to instrumental reason. This situation gave place to those critics of reason to declare "the end of history". However, this paper aims to review the idea of progress considering the ethics of discourse as a conceptual framework, as in Appel and Habermas, who aim to address and revalue the emancipatory potential of reason and hold a perspective of sense for human history.

PALABRAS CLAVE: sentido de la historia, progreso, racionalidad comunicativa, emancipación.

KEYWORDS: sense of history, progress, comunicative rationality; emancipation.

RECEPCIÓN: 26 de septiembre de 2007.

ACEPTACIÓN: 22 de mayo de 2008.

* Profesor-Investigador de la Universidad Intercontinental. 
NOTAS

\section{LA NOCIÓN DE PROGRESO DESDE} APEL Y HABERMAS*

\section{Introducción}

$\mathrm{P}$ ara referirse al acto de caminar, los latinos usaban la raíz grad-, que se encuentra en gradi (caminar, dar pasos). El participio pasivo de este verbo, gressus, dio lugar, mediante el uso de prefijos, a numerosas palabras en las lenguas romances. Así, de la idea de dar pasos hacia adelante, surgió la palabra 'progreso' (progressus, participio de progredi, ir hacia delante) ${ }^{1}$ de la idea de dar pasos hacia atrás, surgió 'regreso' (regressio, regressus). En la Ilustración, la historia comenzó a verse como lineal e irreversible y la idea de progreso se elevó a la categoría de concepto clave en la historiografía e

* El título original es: "Reinterpretación ética de progreso desde la ética del discurso de Apel y Habermas", reducido por razones de espacio.

${ }^{1}$ Cfr., S. Rodríguez Castro, Diccionario etimológico griego-latín del español, 2006, México, Esfinge, p. 200. indicaba la existencia de un sentido de mejora en la condición humana. Las interpretaciones de varios estadios de la humanidad de Condorcet o el positivismo de Comte fueron de las más importantes concepciones de la historia que confiaban en el progreso social. La especie humana sería concebida como perfectible, y su naturaleza podía ser desarrollada indefinidamente mediante una correcta pedagogía, con tal de adquirir la capacidad de pensar por sí mismo y salir de la minoría de edad. A partir de esta época, la noción de progreso se asoció con el despliegue de la razón en un proceso indefinido e infinitamente perfectible, como indefinidas son las potencialidades de la razón humana. Las filosofías de la historia del siglo XVIII y principios del XIX acusaban un optimismo y confianza extremos en que dicho despliegue de la razón llevaría al ser humano hacia su emancipación intrahistórica. 
NOTAS

Pero, en la segunda mitad del XIX, dicha confianza empezó a ser cuestionada desde distintos frentes: la escuela de la sospecha, la teoría crítica de la sociedad, la hermenéutica de la facticidad, el postestructuralismo. Estas críticas se vieron reforzadas por las catástrofes de los siglos XIX $\mathrm{y} X \mathrm{X}$, haciendo ver que la historia no tenía un sentido, que el progreso no se identificaba con el despliegue de la razón y que la idea de historia de Occidente es, de hecho, un concepto con una fuerte carga ideológica y legitimadora que tejió una visión falseada del devenir humano.

En el presente trabajo coincidimos en que no hay un sentido para la historia, al menos no en términos metafísicos o teológicos; sin embargo, suponemos que lo debe tener en términos éticos, en los cuales el progreso no será una fuerza ciega sino un ideal regulativo, cuya realización deberá depender exclusivamente de la buena voluntad humana. La historia se ha dirigido a un punto que no ha sido el óptimo porque el ser humano es defectible; sin embargo, su estructura revela posibilidad, perfectibilidad constante y abierta. ${ }^{2}$ En esta base antropológica asentamos este escrito para proponer, no sólo una interpretación, sino más bien una

${ }^{2}$ Cfr., J. Habermas, "¿Aprendemos de las catástrofes? Diagnóstico y retrospectiva de nuestro breve siglo Xx", en Nexos y El Mercurio, 20-091998, Universidad de Magdeburgo. reconstrucción de la categoría del progreso, desde un concepto de razón que, por definición, reclama reciprocidad, una razón dialógica, que es al mismo tiempo razón ética, tal como es expuesta por Jürgen Habermas y Karl-Otto Apel.

\section{"El fin del sentido emancipador de la historia"}

El problema del fin de la historia fue planteado en el siglo XX de manera radicalmente distinta a como se planteó en el siglo XIX. ${ }^{3}$ El fin de la historia no es su realización o su plenitud, sino su agotamiento, su fracaso. Jean-Françoise Lyotard y Gianni Vattimo, cada uno por su lado, hacen ver que los acontecimientos catastróficos del siglo XX les 'conceden razón' y les 'hacen justicia' a quienes han abjurado de la 'Razón'. Lyotard hizo ver que los metarrelatos que han marcado a la Modernidad, tales como: "emancipación progresiva de la razón y de la libertad, emancipación progresiva del trabajo, enriquecimiento de toda la humanidad a través del progreso de la tecnociencia, etc.", se articularon en el llamado 'proyecto de la

${ }^{3}$ Cfr., Javier Sádaba, “¿El fin de la historia? La crítica de la posmodernidad al concepto de historia como metarrelato", en Manuel Reyes Mate (ed.), Filosofia de la Historia, 1993, Valladolid, Trotta, p. 193-205. 
modernidad', orientado hacia el futuro, en cuyo corazón se encuentra la noción de 'progreso'. Dicho proyecto no sólo no ha sido llevado a su término sino que es un proyecto destruido, liquidado. ${ }^{4}$ Vattimo critica las representaciones ideológicas de la historia que pretendían garantizar las metas y su sentido emancipador. Para él, nos encontramos en la época de la posthistoria, que es el vaciamiento de todo contenido. La historia se convirtió en la historia del progreso: pero el ideal del progreso es también algo vacío y su valor final es el de realizar condiciones en que sea posible un nuevo progreso. Y éste, privado de una meta, llega a ser también la disolución del concepto mismo de progreso, tal y como ocurre en la cultura entre los siglos XIX y XX. ${ }^{5}$

Compartimos las observaciones críticas, sin embargo, consideramos que los planteamientos de estos dos autores posmodernos -siendo coherentes-, no pueden conducir a nada: ante la inminente pérdida de vigencia de las ideologías y metarrelatos, habría que ceder a la pluralidad e inconmensurabilidad de los juegos

${ }^{4}$ Jean-Françoise Lyotard, La posmodernidad. Explicada a los niños, 1995, Barcelona, Gedisa, p. 30. Cfr., Lyotard, La condición posmoderna. Informe del Saber, 1987, Madrid, Cátedra.

${ }^{5}$ Gianni Vattimo, El fin de la Modernidad. Nihilismo y hermenéutica en la cultura posmoderna, 1987, Barcelona, Gedisa, p. 14-5. Cfr. G. Vattimo, "El fin del sentido emancipador de la historia”, en El Pais, 6 de diciembre de 1986. lingüísticos; ante los millares de microhistorias, todas igualmente legítimas, ante el relativismo e individualismo. El desencanto ante la razón moderna sitúa al ser humano de hoy en una actitud más cómoda: el conformismo y la resignación ante la imposibilidad de cambiar las cosas y la búsqueda de placeres que reducen la vida a lo trivial. Por otro lado, hay que decir que la postmodernidad anula toda posibilidad de crítica, puesto que no admite criterio alguno de referencia, y no puede haber crítica sin criterio. No ofrece un criterio para discernir las injusticias sociales, nos deja a merced de lo existente y sin posibilidades de crítica racional; por eso, Habermas no duda en denominarlo 'pensamiento neoconservador'. ${ }^{6}$ Pero ni el azar ni el nihilismo ni la circularidad pueden constituir el destino humano; tampoco la injusticia, el sufrimiento ni la miseria. ¿Qué tal un eterno retorno así de miserable? Los mismos actores, las mismas guerras, las mismas injusticias, los mismos desencantos. Ya san Agustín había denunciado el carácter inhumano de una concepción de la historia de este talante.

Si Lyotard declara que 'Auschwitz' es el nombre paradigmático del fracaso de la Modernidad, no podemos resignarnos únicamente a saber, no

${ }^{6} \mathrm{~J}$. Baudrillard et al., La posmodernidad, 1988, México, Kairós, p. 25. 
NOTAS

podemos dejar que la injusticia tenga la última palabra. Hay una exigencia ética en esa declaración: buscar que las cosas sean de otra manera o por lo menos buscar que esa historia no vuelva a repetirse, porque, hoy en día, Auschwitz se sigue reproduciendo bajo nuevas formas. ${ }^{7}$

\section{La idea de progreso y de historia sometida a crítica}

Haciendo eco de los planteamientos de Horkheimer y Adorno, es necesaria la desmitologización y desescatologización de la Ilustración, del proyecto emancipador de la historia y de su inherente noción del progreso. ${ }^{8}$ Es preciso considerar críticamente este proyecto, con todo y sus limitaciones, lo cual implica el reconocimiento de su incapacidad para responder a las cuestiones del sentido último de la existencia, que permita abrirse a otros discursos y recuperar las aportaciones que sobre esta cuestión ofrecen. ${ }^{9}$ En

${ }^{7}$ Algunas acotaciones críticas sobre los planteamientos de Lyotard y Vattimo se encuentran en J. M. Mardones, "El neo-conservadurismo de los posmodernos", en G. Vattimo y otros, En torno a la posmodernidad, 1990, Bogotá, Anthropos, p. 21-40.

${ }^{8} \mathrm{~J}$. Habermas, El discurso filosófico de la modernidad, 1993, Madrid, Taurus, p. 136.

${ }^{9}$ Horkheimer y Adorno, Dialéctica de la Ilustración. Fragmentos filosóficos, 1998, Madrid, Trotta, p. 61. contra de los rostros irracionales de la postmodernidad, consideramos que no se puede renunciar a la racionalidad, una racionalidad crítica y abierta también a otras formas y dimensiones del pensamiento. El error de la Ilustración fue reducirse a una sola dimensión, la instrumental, y olvidar que la racionalidad parte de la vida y la experiencia, y que la verdad a la que aspira está arraigada en el mundo de la vida. ${ }^{10}$ Esta condición situada de la racionalidad permite resarcir la dicotomía entre teoría y praxis en la existencia intramundana.

Walter Benjamin nos hace ver que la ilustración y su modelo de historia y progreso sólo son erigidos a costa de la ruina, el fracaso, la sangre, la muerte y el olvido de las víctimas de la historia. ${ }^{11}$ El progreso ilustrado ha sacrificado el presente y el pasado en aras de un futuro falso o no esclarecido. Por ello, toda reivindicación del progreso, incluso aquel que se reinterprete éticamente, deberá reconocer el alto precio que se ha pagado, el dolor, el sufrimiento y la muerte: la memoria es la condición de tal reivindicación. La propuesta de Benjamin se puede resumir en la sustitución de la noción

${ }^{10} \mathrm{M}$. Horkheimer, Crítica de la razón instrumental, 1973, Buenos Aires, Sur, p. 5.

${ }^{11}$ W. Benjamin, "Tesis sobre Filosofía de la Historia”, en Discursos Interrumpidos, 1992, Madrid, Taurus. 
lineal de tiempo que pone la esperanza en la capacidad revolucionaria del futuro, por la idea de que el presente tiene una capacidad revolucionaria que consiste en la irrupción en él de un pasado inédito, fracasado. ${ }^{12}$ Paradójicamente, este pasado fracasado, es el único que tiene esperanza; pero si los que recuerdan son las víctimas, y éstas no están en posibilidad de testimoniar, se hace necesario que otros 'recuerden', esto es, se necesita una forma de solidaridad entre las generaciones, ya que mientras la causa de los vencidos de la historia y del progreso no sea atendida, los vencedores seguirán causando más víctimas. Este es el relato de la pasión de la humanidad, para la creación de formas de vida más humanas. Destaca Benjamin que para una vida social más feliz, libre, justa y solidaria, es necesario traer a la memoria el recuerdo de la historia del sufrimiento de la humanidad y la solidaridad compasiva con los muertos y vencidos. ${ }^{13}$

\section{Relectura de la historia y de la idea de progreso}

A partir de las críticas de Benjamin y de Horkheimer y Adorno, surge la necesidad de restaurar el sentido de la historia, una historia que no es sagrada, sino profana, laica o secular, que tiene no una visión desmesuradamente optimista, sino que está apoyada en la constante autocrítica y en la esperanza de que la buena voluntad humana pueda hacerse efectiva. Es una historia con un sentido emancipador.

Este sentido de la historia no puede inspirarse sino en los ideales propugnados por la misma Ilustración, con todo y su adjunta idea de progreso, lo cual implica redefinir esta idea, someterla a crítica, acotar sus alcances y entenderla también en sentido profano. Pero esto no es posible si no partimos de otro paradigma distinto al de la Ilustración: el paradigma de la conciencia, del pensamiento objetivante y del solipsismo metódico, ya que éste ha sido el principal factor de la autodestrucción de la Ilustración, de su transformación a dogma y de su reducción a razón instrumental que ejerce voluntad de dominio.

Para apoyarnos en otro paradigma será importante contar con las aportaciones de la filosofía contemporánea: el giro lingüístico, en la vertiente pragmática, y la hermenéutica reconstructiva del sentido. 
NOTAS

\section{La ética del discurso como reivindicación de la racionalidad}

Habermas, por un lado, ha intentado la reivindicación de la razón y de su potencial crítico y emancipador:

En lugar de seguir el camino trazado por Nietzsche de una crítica totalizadora y autorreferencial de la razón [...], y tirándolo todo por la borda, es mucho más prometedor intentar lograr esta finalidad a través del análisis del potencial operativo de la racionalidad que se encuentra $y a$ contenido en la práctica cotidiana de la comunicación. ${ }^{14}$

K.O. Apel, por el otro, echa mano de las orientaciones filosóficas arriba citadas para comenzar por transformar la filosofía trascendental kantiana, ${ }^{15}$ con tal de mantener la autonomía moral de los individuos y con el fin de superar el solipsismo moral al que evidentemente conducía. Sólo con las herramientas proporcionadas por el pragmatismo peirceano y la hermenéutica es posible elaborar el nuevo paradigma del acuerdo intersubjetivo.

Apel y Habermas proponen como pensamiento postmetafísico la ra-

${ }^{14}$ J. Habermas, "Cuestiones y contracuestiones", en A. Giddens et al., Habermas y la modernidad, 1988, Madrid, Cátedra, p. 312. Cfr., J. Habermas, Teoría de la acción comunicativa, 1989, t. I, Buenos Aires, Taurus.

${ }^{15}$ K.O. Apel, La Transformación de la filosofia, 1985, Madrid, Taurus, 2 tomos. cionalidad comunicativa como la alternativa a la postmodernidad: es un esfuerzo que reivindica a la Modernidad y conduce a hacer valer el principio ético discursivo de la universalización como la medida de la claridad racional, democrática y humana, sin caer en las acusaciones de etnocentrismo, fundamentalismo, uniformización de las diversas formas de vida, sometimiento de los diversos tipos de racionalidad a uno sólo, imposición de grandes relatos en nombre de la emancipación, etc. ${ }^{16}$ Esta propuesta sostiene una universalidad procedimental y no sustantiva, que debe mantener el respeto al pluralismo de las formas de vida. Es una práctica intramundana, y no meramente académica, pues el mundo de la vida se nutre de la práctica comunicativa y ésta es alimentada por aquél.

Apel y Habermas, aunque más el primero que el segundo, quieren llevar a cabo la transformación de la filosofía y tienen de fondo la intención de recuperar la dimensión crítica de la filosofía, como 'guardiana' de la racionalidad, y esto a su vez compromete una tarea de fundamentación trascendental, para asegurar un punto de apoyo normativo para la afirmación del sentido emancipador de la historia y para dar

${ }^{16} \mathrm{~J}$. Habermas, Pensamiento postmetafisico, 1990, Madrid, Taurus. 
continuidad al proyecto inconcluso de la Modernidad. ${ }^{17}$

Se busca fundamentar el conocimiento, el entendimiento mutuo y la formación del consenso sobre reglas de todo discurso argumentativo, como evidencias y como condiciones a priori. ${ }^{18} \mathrm{El}$ carácter a priori de estas condiciones no tiene que ver con ninguna anterioridad metafísica, sino con una anterioridad inteligible, ${ }^{19}$ que se presupone en todo

${ }^{17}$ Apel, La transformación de la filosofía, op. cit., t. I, p. 9.

${ }^{18}$ Cfr., Apel, "El problema de la fundamentación filosófica última desde una pragmática trascendental del lenguaje", en Estudios filosóficos, 1987, n 102, vol. XXXVI, p. 251-300.

${ }^{19}$ Resulta pertinente aclarar qué significa $a$ priori en Apel: desde el s. XVII, el término a priori se ha aplicado en la historia de la filosofía cuando se considera la manera como llegamos a saber la verdad de una proposición: son a priori aquellos enunciados cuya verdad se origina en la misma razón. A priori significa, por tanto, con anterioridad a la experiencia, o independientemente de ella, no en sentido psicológico, sino en sentido lógico y hasta metafísico: no es necesario recurrir a la experiencia para conocer que un enunciado es verdadero. Los enunciados cuya verdad se conoce independientemente de la experiencia, por sólo la razón, son al mismo tiempo enunciados necesariamente verdaderos (no pueden ser falsos y su opuesto es una autocontradicción). Lo necesario puede conocerse a priori. No se precisa recurrir a la experiencia para saber con certeza que "cuando alguien es A, entonces no es B", basta con conocer sólo el significado de los términos. A priori, en Apel, se entiende como aquellos presupuestos, no lógicos ni metafísicos, sino preteóricos, pertenecientes al ámbito de nuestra facticidad constituyente y, por tanto, irrecusables e irrebasables. Lo a priori es fáctico, más aún, pragmático. No obstante, en tanto irrenunciables, tienen un carácter trascendental, puesto que son condiciones de diálogo que busca la concertación, a saber: todo el que participa en la praxis de la argumentación tiene que haber aceptado esas condiciones, que son normativas, para que haya entendimiento mutuo que, de lo contrario, haría imposible la comunicación. ${ }^{20}$

Con Wittgenstein y más allá de Wittgenstein, Apel sostiene que como todo juego lingüístico es una forma de vida que no puede jugarse solipsistamente, será imprescindible la concertación lingüística: dada la imposibilidad del lenguaje privado, estamos condenados $a$ priori al acuerdo intersubjetivo. $\mathrm{Y}$ como acabamos de mencionar, este acuerdo supone la admisión a priori de reglas de la argumentación. Este principio wittgensteiniano es una primera condición de posibilidad del acuerdo. Otra condición es que lo anterior nos coloca en una comunidad real de comunicación, dialogante, que somete a discusión y crítica sus argumentos; esta comunidad real es condición trascendental del acuerdo y es un a priori pragmático. Ahora bien, ella se identifica con el género humano o con la sociedad. Una tercera condición trascendental es la asunción de una comunidad ideal de comunicación; ésta es un postulado de la razón dialógica o

posibilidad de cualquier cosa que se derive de, o se apoye en ellos.

${ }^{20}$ Apel, Teoria de la verdad yética del discurso, 1991, Barcelona, Paidós/ICE-UAB, p. 147 s. 
NOTAS

comunicativa en el sentido de que hay una exigencia de que la comunidad real de comunicación establezca efectivamente acuerdos y consensos, y de que encarne ese ideal, si es que buscamos que con el lenguaje haya entendimiento recíproco.

Mediante estas condiciones nos situamos en un escenario en el que es posible reconocer el sentido, la verdad y la validez de nuestras proposiciones argumentativas. ${ }^{21}$ Además, podemos incluir entre esas condiciones los presupuestos pragmáticos de la semiótica: la estructura triádica de la función sígnica - signo, significante e intérprete del signo-, puesto que esta relación se presupone en cualquier acto del habla. Desde esta estructura triádica, todo argumento es interpretable y constituye la unidad básica de los pensamientos intersubjetivamente válidos. Cuando se argumenta se supone implícitamente esta función trascendental sígnica. ${ }^{22}$ Otra condición trascendental son los mismos argumentantes, en cuya función argumentativa se hacen saber las pretensiones de verdad y validez, por medio de proposiciones, argumentos, sistemas lingüísticos, que pueden ser confirmados, discutidos o refutados por todo miembro de la comunidad de argumentación. ${ }^{23}$

${ }^{21}$ Apel, La transformación de la filosofia, op. cit., t. I, p. 55-64.

${ }^{22}$ Ibid., p. 264-306.

${ }^{23}$ Ibid., t. II, p. 380.
Desde este punto de vista, todo conocimiento que pretenda ser intersubjetivamente válido, debe respetar esas condiciones a priori trascendentales del acuerdo. El lenguaje, que siempre es lenguaje común, según el juego lingüístico del acuerdo, no puede prescindir de exigencias críticas y normativas en la racionalidad comunicativa. La condición de verdad de un enunciado consiste en el consentimiento potencial de todos los dialogantes potenciales, es decir, en la expectativa de alcanzar un consenso racional. El sentido de la verdad consiste en que siempre que entremos en un discurso pensamos que puede alcanzarse un acuerdo fundamentado, pero las condiciones de tal acuerdo racional no dependen de un consenso sino que son condiciones a priori supuestas en él.

\section{La racionalidad comunicativa como fundamentación de la ética}

Peirce planteaba la postulación de una comunidad ilimitada de investigación en la que se sustentaba el acuerdo intersubjetivo de la práctica de la investigación tendiente a la verdad. Ésta es transformada por Apel por una comunidad ilimitada (o ideal) de comunicación, que también tiende a la verdad pero en su acepción moral y no epistemológica. 
La transformación de la filosofía hace derivar dos máximas para la ética que prescriben su marco normativo, a saber: 1) la conservación del género humano como comunidad real de comunicación; y, 2) el esfuerzo por realizar la comunidad ideal de comunicación en la real. ${ }^{24}$

La transformación de la filosofía propone la transmutación del desinterés de los investigadores de sus problemas individuales al adoptar la causa comunitaria de la búsqueda de la verdad "siempre en camino y a lo largo de él", en la disposición a la argumentación intersubjetiva que busca la transubjetividad de la defensa de intereses comunes. No se trata de suprimir la autonomía individual y los intereses finitos, se trata de trascenderlos en aras de intereses comunes, siempre y cuando se argumente su exigencia y necesidad.

La racionalidad comunicativa o dialógica soporta una dimensión alterativa innegable. Esto es lo que da pie a la fundamentación de una ética del discurso, como propuesta postmetafísica, que se suma a las ciencias crítico-reconstructivas (o emancipatorias) de las que habló Habermas ${ }^{25}$ y que se tornan en alternativa para la reconstrucción del sentido, de la verdad y validez.

${ }^{24}$ Ibid., p. 409.

25 J. Habermas, Conocimiento e interés, 1990, Madrid, Taurus.
Esta ética tendrá como presupuestos los mismos del diálogo y del entendimiento recíproco, las condiciones trascendentales y de posibilidad del acuerdo intersubjetivo. Sus principios son: a) autorrenuncia frente a los propios intereses y convicciones, que en razón de su limitación no pueden imponerse como únicos; b) reconocimiento del derecho de los miembros de la comunidad real de comunicación de exponer sus argumentos con su consecuente obligación de justificarlos; c) compromiso en la búsqueda de la verdad, porque sólo por medio de los dialogantes reales en una comunidad real, aunque falible, puede hallarse la verdad; d) esperanza en el consenso, no como ilusión vana, sino esperanza crítica que garantice los consensos fácticos; $y, e)$ consenso solidario en una perspectiva teleológico-moral.

La ética del discurso puede entenderse como un proyecto futuro, en el que se realice la comunidad ideal de comunicación en la real y que se apoye en la esperanza de quien confía en la racionalidad humana y en la humana solidaridad. ${ }^{26}$ Desde el punto de vista de este proyecto se puede seguir defendiendo el programa ilustrado de la universalidad de la

${ }^{26}$ Cfr., J. A. Pérez Tapias, "Más allá de la facticidad, más acá de la idealidad”, en Blanco Fernández, Pérez Tapias, Sáez Rueda (eds.), Discurso y realidad. En debate con K.O. Apel, 1994, Madrid, Trotta, p. 207-27. 
NOTAS

razón y de su importancia para una vida más racional, justa y humana, aunque esta universalidad deberá adecuarse a la pluralidad de formas de vida concretas y tendrá que buscar vías de mediación con las tradiciones culturales concretas: el diálogo y el acuerdo intersubjetivo (e intercultural). La universalidad de la razón se asienta sobre estructuras a priori de la razón comunicativa o dialógica.

\section{Reconstrucción del sentido de la historia y de la idea del progreso}

Es posible, entonces, llevar a cabo una nueva interpretación de la idea de progreso desde la ética del discurso. El progreso era entendido por los ilustrados como una ley necesaria que conducía a la historia humana hacia la felicidad terrena, en un movimiento en que las épocas superiores se hallaban más cerca de la verdad. Se concebía como un proceso real, cuya ley estaba inscrita en el orden natural de las cosas: continuo, irreversible y acelerado; y necesariamente se dirigía hacia lo mejor, emulando las capacidades humanas, especialmente la razón, que son ilimitadamente perfectibles. Esta reinterpretación del progreso no se puede hacer al margen de la razón.

Si el progreso de la historia se identifica con el de la razón que se desplie- ga, y ésta lo hace a partir de la praxis comunicativa -de acuerdo a la reconstrucción de la propuesta apeliana-, entonces podemos reconsiderar esta noción a partir de una lectura postmetafísica, para postularlo como ideal regulativo. La idea de progreso tiene que replantear sus premisas: la razón continuamente ampliaba sus horizontes, pero ella no puede seguir siendo pensada como razón monológica, autosuficiente, insolidaria y solipsista; es ante todo razón situada, mediada hermenéuticamente $\mathrm{y}$, sobre todo, es razón comunicativa o dialógica. Sólo puede desplegarse efectivamente por medio del ejercicio comunicativo, en el que se exponen argumentos, se defienden y justifican, pero también en donde pueden ser interpelados, refutados o perfeccionados, en suma, en donde es posible alcanzar la verdad. Este despliegue de la razón, así visto, es un indicio de progreso; sólo que no es un movimiento inexorable, sino finito, limitado, contingente, que requiere de la buena voluntad y de la solidaridad humanas, también finitas y falibles.

En la Ilustración, la razón que impulsaba al progreso histórico adquiría una conciencia crítica de su autonomía, cada vez mayor, frente al irracionalismo. Podemos decir que la afirmación de esta autonomía, según la propuesta apeliana, no exime de responsabilidad social; por el contrario, compromete en la medida en 
que el ser humano, en tanto racional, es-en-el-mundo, y es-con, por lo que la autonomía tiene la exigencia ética de autotrascenderse hacia una responsabilidad que nuestra condición social anticipa. Esto también se constata en la praxis comunicativa, que busca el entendimiento mutuo y no sólo imponer egoístamente los intereses individuales.

La razón haría al hombre mejor moralmente, no sólo de manera individual sino social y colectivamente, lo que está supuesto en los postulados anteriores. Este proceder hacia lo mejor es un imperativo ético y axiológico.

El progreso de la historia dependerá del progreso de la razón práctica y comunicativa, y como el progreso de esta razón es indefinidamente perfectible, también lo será el progreso de la historia; sin embargo, cabe decir, el progreso tanto de la razón como de la historia, al depender del ser humano, es discontinuo, no lineal o metafísicamente necesario.

La noción de progreso puede identificarse con el postulado de la comunidad ideal de comunicación, en la medida en que ésta orienta a la comunidad real hacía sí como su ideal regulativo. ${ }^{27}$ La comunidad ideal de comunicación constituye la meta que da sentido al movimiento humano

${ }^{27}$ Apel, La transformación de la filosofía, op. cit., t. II, p. 407-8. como comunidad real. En la medida en que ésta se aproxime a la primera podemos decir que el movimiento es progresivo. ${ }^{28}$ Lo que define al progreso no es el movimiento sino la meta que, en este caso, es ese ideal regulativo: si hay movimiento hacia la meta, hay progreso. La comunidad ideal de comunicación no sólo es un a priori del diálogo y el acuerdo intersubjetivo, sino que puede servir de a priori regulativo para reconstruir el sentido emancipador de la historia y para traducir la idea de progreso.

El progreso, en sentido moral y humano, es un postulado exigido por la relación asintótica y dialéctica entre la comunidad real y la comunidad ideal de comunicación. A su vez, el postulado trascendental de la comunidad ideal para el acuerdo, reclama que haya un movimiento hacia ella; este postulado encarna una serie de valores. Si el ser humano determina racional y voluntariamente esta meta, privilegiando un sentido sobre otro, entonces piensa que lo establecido ha de ser lo más valioso sobre cualquier otra cosa.

Ello da pie a una escala jerárquica de valores y el progreso se da cuando se asciende a valores considerados superiores en dicha escala. De ellos, los más elevados, nunca definitivos, son: a) la conservación del género humano como comunidad

${ }^{28}$ Ibid., p. 409. 
NOTAS

real; b) su aproximación a la comunidad ideal; y, c) la responsabilidad solidaria que supera el solipsismo metódico. Estos valores, como cualquier otro, son convencionales; sin embargo, pueden ser aprobados intersubjetiva y pragmáticamente y podrán cargárseles de contenido. No obstante, bajo la premisa de la comunidad real de argumentantes, son asumidos como incondicionados y como condición de posibilidad para hacer, de esta comunidad real, una mejor.

\section{Acotaciones finales}

El progreso, por definición, es inconcluible, a menos que la comunidad ideal sea realizada plena y absolutamente y así llegue a su fin la comunidad real; es humanamente imposible. Nada ni nadie garantiza que ese fin llegue, lo cual le da consistencia al carácter normativo que adquiere esa noción. Sabemos -y deseamos- hacia dónde debe dirigirse el progreso; pero supone la libertad y la buena voluntad humana y la responsabilidad solidaria para que se siga sosteniendo. Dado que el concepto de progreso es una idea que tiene un carácter ilimitado, y como la condición humana es finita y limitada, es necesario que esa asimetría no signifique una pasión inútil; para ello, es necesario sobrecargarle al progreso la exigencia moral de contribuir a la realización del individuo y a la conservación y promoción de la especie. Aunque ilimitado, el progreso humano es contingente, falible y discontinuo; por ello, no debemos esperar la falsa ilusión de la erradicación total de la injusticia, la desigualdad, la violencia, ni la irrupción de un paraíso terrenal. Esto seguirá existiendo porque es parte de la condición humana; sin embargo, a su vez, lo hace vigente y éticamente necesario, y desde esta perspectiva tiene sentido el postularlo como ideal regulativo que reclama siempre la buena voluntad para recomponer el curso de las cosas. En ello descansa la radical intención utópica de esta noción del progreso, reinterpretada así desde la ética del discurso. ${ }^{29}$

El postulado del progreso no es garantía para ningún optimismo racionalista, puesto que la esperanza en la que se apoya y que tematiza no puede ser otra que esa 'esperanza paradójica' a la que sólo puede corresponder un 'optimismo trágico'. Tal es el optimismo propio de una utopía que tiene un soporte críticohermenéutico que le recuerda que la tradición emancipadora, gracias a la cual podemos seguir hablando

${ }^{29}$ Cfr., J. A. Pérez Tapias, "El aguijón apocalíptico y la Filosofía de la Historia", en Diálogo Filosófico, n 43, 1999, p. 71-88; J. A. Pérez Tapias, "Cambio de paradigma en el pensar utópico", en Diálogo Filosófico, n 44, 1999, p. 180-210. 
de progreso y postulándolo, es una tradición cargada de sufrimiento $y$, por lo mismo, de anhelo de justicia, como Benjamin nos hace recordar. El postulado del progreso que nos proyecta esperanzados hacia adelante no es el postulado de ningún utopismo futurista, sino el postulado de una utopía cuyo 'aún-no realizado’ es compromiso para un aquí y ahora que no pierde de vista que la 'chispa de la esperanza' viene de atrás y que buena parte de su fuerza movilizadora se la debe a la "imagen de los antepasados oprimidos". La utopía de una ética dialógica de la responsabilidad solidaria no debe dejar de repetirse una y otra vez que "sólo por aquéllos sin esperanza nos es dada la esperanza". ${ }^{30}$ 
La reproducción total o parcial de este artículo se podrá hacer si el ITAM otorga la autorización previamente por escrito. 